\title{
BAGAN PENGERINGAN DASAR 12 JENIS KAYU DARI INDONESIA
}

\author{
(Basic Drying Schedules of 12 Indonesian Wood Species)
}

Oleh/By:

Efrida Basri

\begin{abstract}
Kiln drying requires proper drying schedule which is based on the wood properties, especially its drying properties. The purpose of this research was to establish the basic drying schedule of 12 wood species from Indonesia, i.e. West Nusa Tenggara, West Java, Aceh and West Kalimantan, based on the drying properties. The determination of drying schedule was initiated by examining wood drying properties using bigh temperature or quick drying test method (at $100^{\circ} \mathrm{C}$ temperature).

Results indicated that the drying properties of each wood showed different respons to bigh temperature. The best drying property of 12 wood species investigated was bayur (Pterospermum elongatum) wood; while both mahang (Macaranga hypoleuca) and menjalin (Xanthophyllum flavescens) wood were the poorest. Based on drying properties, all samples of 12 wood species investigated is classified into 8 drying schedule groups.
\end{abstract}

Keywords: Wood species, high temperature, drying property, drying schedule

\begin{abstract}
ABSTRAK
Pengeringan kayu dalam kiln drying memerlukan bagan pengeringan yang berbasis sifat-sifat kayu, terutama sifat pengeringannya. Tujuan penelitian ini adalah menetapkan bagan pengeringan dasar 12 jenis kayu dari beberapa daerah di Indonesia, yaitu Nusa Tenggara Barat, Jawa Barat, Aceh dan Kalimantan Barat berdasarkan sifat pengeringannya. Penetapan bagan pengeringan diawali dengan menguji sifat pengeringan kayu menggunakan metode suhu tinggi (suhu $100^{\circ} \mathrm{C}$ ).

Hasil penelitian menunjukkan bahwa setiap jenis kayu memiliki respons yang berbeda terhadap perlakuan suhu tinggi. Dari 12 jenis kayu yang diteliti, kayu bayur (Pterospermum elongatum) memiliki sifat pengeringan terbaik, sedangkan kayu mahang (Macaranga bypoleuca) dan menjalin (Xanthophyllum flavescens) yang terburuk. Berdasarkan sifat pengeringan tersebut, maka ke 12 jenis kayu yang diteliti diklasifikasikan ke dalam 8 kelompok bagan pengeringan.
\end{abstract}

Kata kunci: Jenis kayu, suhu tinggi, sifat pengeringan, bagan pengeringan 


\section{PENDAHULUAN}

Bagan pengeringan merupakan salah satu faktor penting yang menentukan keberhasilan pengeringan kayu dalam ruangan/dapur pengering yang memiliki sistem pengaturan suhu dan atau kelembaban, seperti kiln drying, debumidifier atau alat pengering kombinasi tenaga surya dan panas dari tungku bakar. Bagan pengeringan yang lazim digunakan di industri pengolahan kayu di Indonesia adalah bagan pengeringan berbasis kadar air, di mana setiap langkah pengaturan suhu dan kelembaban udara berpatokan pada tingkat kadar air rata-rata kayu yang sedang dikeringkan (Rasmussen, 1961; Kadir, 1975). Sampai saat ini, bagan pengeringan berbasis kadar air masih menjadi pegangan bagi industri pengolah kayu tropis yang menggunakan kiln drying, karena risiko kerusakan kayu yang terjadi sangat kecil dan bisa menghemat waktu pengeringan. Namun begitu, dalam penerapannya perlu dimodifikasi, terutama dalam ukuran sortimen. Untuk itu dibutuhkan operator yang mumpuni yang juga memiliki pengetahuan dasar tentang sifat-sifat kayu (Terazawa, 1965; Perré, 2001).

Dalam tulisan ini disajikan hasil penelitian bagan pengeringan dasar (basic drying schedule) 12 jenis kayu yang dapat digunakan dalam dapur pengering konvensional (kiln drying) atau alat pengering lain yang memiliki sistem pengontrolan suhu dan kelembaban. Bagan tersebut diharapkan bisa menjadi pedoman bagi operator yang akan mengeringkan jenis kayu yang sama.

\section{BAHAN DAN METODE}

\section{A. Bahan}

Kayu yang diteliti terdiri dari 12 jenis yang berasal dari hutan alam di beberapa daerah di Indonesia, yaitu: kayu sepalis, menjalin, bayur, perepat laut, petai dan kenanga dari Aceh; kayu putat dari Jawa Barat; kayu tapos, dahu, mahang dan saga dari Kalimantan Barat; dan kayu jirak dari Nusa Tenggara Barat. Penelitian dilakukan di laboratorium Pengeringan Kayu P3HH Bogor. Peralatan yang digunakan dalam penelitian antara lain: timbangan elektronik, oven memmert, dial caliper dan mistar ukur.

\section{B. Metode}

Penetapan bagan pengeringan diawali dengan pengujian sifat pengeringan kayu pada suhu tinggi. Untuk keperluan tersebut, dari setiap jenis kayu dibuat 10 contoh uji berukuran 2 $\mathrm{cm} \times 10 \mathrm{~cm} \times 20 \mathrm{~cm}$. Percobaan dilakukan dengan mengeringkan contoh uji dalam oven pada suhu konstan $100^{\circ} \mathrm{C}$. Pengamatan pecah ujung dan permukaan pada contoh uji kayu dilakukan setiap 2-3 jam hingga kerusakannya mencapai batas maksimum. Selanjutnya semua contoh uji dikeringkan hingga mencapai berat kering tanur (kadar air kayu $0 \%$ ) dan diukur deformasi pada arah radial (tebal) dan pecah pada bagian dalam kayu. Penilaian sifat pengeringan kayu didasarkan pada kehadiran 3 jenis cacat tersebut dan tingkat kerusakannya berdasarkan metode Terazawa (1965) yang telah dimodifikasi (Tabel 1-3). Berdasarkan data tersebut, kemudian ditetapkan nilai suhu serta kelembaban minimum dan maksimum 
pengeringan yang sesuai untuk setiap jenis kayu (Tabel 4). Dengan bantuan data suhu dan kelembaban yang dibuat oleh Forest Products Laboratory Madison (Torgeson, 1951 dalam Basri, et al., 2000), ditetapkan bagan pengeringan dasar untuk 12 jenis kayu yang diteliti.

Tabel1. Pecah ujung dan/atau permukaan pada contoh uji kayu dan klasifikasi sifat pengeringan

Table. End and/or surface checks in wood sample and drying property classification

\begin{tabular}{|c|c|c|}
\hline Pecah (Checks), $\%$ & $\begin{array}{c}\text { Kelas } \\
(\text { Class })\end{array}$ & Sifat pengeringan (Drying property) \\
\hline $0-5$ & I & Sangat baik (Very good) \\
\hline$>5-10$ & II & Baik (Good) \\
\hline$>10-20$ & III & Agak baik (Rather good) \\
\hline$>20-30$ & IV & Agak buruk (Rather poor) \\
\hline$>30-50$ & V & Buruk (Poor) \\
\hline$>50-70$ & VI & Sangat buruk (Very poor) \\
\hline$>70$ & VII & \\
\hline
\end{tabular}

Tabel 2. Perubahan dimensi (deformasi) pada arah radial contoh uji kayu dan klasifikasi sifat pengeringan

Table 2. Deformation in radial direction of wood sample and drying property classification

\begin{tabular}{|c|c|c|}
\hline $\begin{array}{c}\text { Perubahan dimensi } \\
\text { (Deformation), mm }\end{array}$ & $\begin{array}{c}\text { Kelas } \\
(\text { Class })\end{array}$ & Sifat pengeringan (Drying property) \\
\hline $0-0,3$ & I & Sangat baik (Very good) \\
\hline $0,3-0,6$ & II & Agak baik (Rather good) \\
\hline $0,6-1,2$ & III & Sedang (Fair) \\
\hline $1,2-1,8$ & IV & Agak buruk (Rather poor) \\
\hline $1,8-2,5$ & V & Buruk (Poor) \\
\hline $2,5-3,5$ & VI & Sangat buruk (Very poor) \\
\hline$>3,5$ & VII & \\
\hline
\end{tabular}

Keterangan (Remark): ${ }^{1)}$ Perubahan dimensi ditentukan berdasarkan perbedaan 2 ukuran tebal pada arah radial kayu (Deformation was based on difference of 2 tickness in radial direction of wood) 
Tabel3. Jumlah cacat pecah pada bagian dalam contoh uji kayu dan klasifikasi sifat pengeringan

Table 3. Total defect of boneycombing checks in wood sample and drying property classification

\begin{tabular}{|l|c|c|}
\hline \multicolumn{1}{|c|}{ Pecah dalam (Honeycombing) } & Kelas & Sifat pengeringan (Drying property) \\
\hline 0 & I & Sangat baik (Very good) \\
\hline 1 besar (major) atau/or 2 kecil (minors) & II & Baik (Good) \\
\hline 2 besar (majors) atau/or $4-5$ kecil (minors) & III & Agak baik (Rather good) \\
\hline 4 besar (majors) atau/or 7 - 9 kecil (minors) & IV & Sedang (Fair) \\
\hline $6-8$ besar (majors) atau/or 15 kecil (minors) & V & Buruk (Poor) \\
\hline 17 besar (majors) atau/or kecil (minors) & VI & Sangat buruk (Very poor) \\
\hline
\end{tabular}




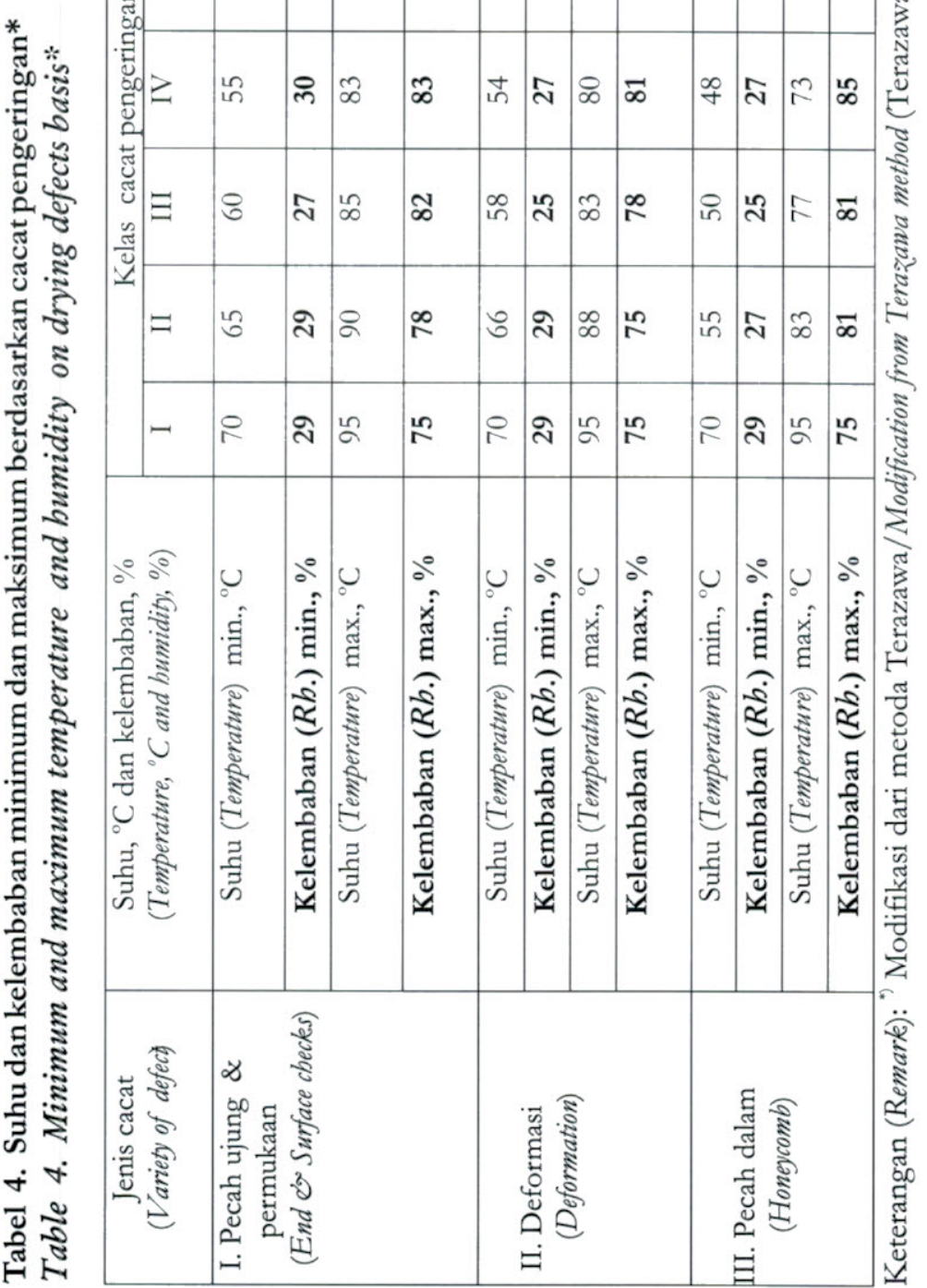




\section{HASIL DAN PEMBAHASAN}

\section{A. Sifat Pengeringan}

Data hasil pengujian sifat pengeringan kayu serta penetapan suhu dan kelembaban minimum-maksimum pengeringan berdasarkan jenis dan tingkat cacat dapat dilihat pada Tabel 5 .

Kayu mahang, meskipun mempunyai berat jenis (BJ) ringan (BJ 0,31), namun sifat pengeringannya jauh di bawah kayu sepalis yang BJ-nya sangat tinggi (BJ 0,88). Hal ini menunjukkan BJ bukan satu-satunya penentu sifat pengeringan. Menurut Bramhall and Wellwood (1976), selain BJ, struktur anatomi kayu juga mempengaruhi proses pengeluaran air dari dalam kayu. Faktor anatomi yang berperan dalam pengeringan kayu di antaranya adalah jaringan pembuluh, dinding serat, parenkim, dan jari-jari (Panshin and de Zeeuw, 1969). Oleh karena itu jika penetapan bagan pengeringan kayu hanya berdasarkan pada kekuatan kayu yang ditunjukkan dari nilai BJ-nya, maka kemungkinan kerusakan terhadap kayu yang dikeringkan tidak bisa dihindari. Sebagai contoh kayu sendok-sendok (Endospermum malaccense) yang memiliki tekstur dan warna serta kekuatan kayunya mirip dengan kayu ramin (Rulliaty, 1988) ketika dikeringkan menggunakan bagan kayu ramin, kayu tersebut mengalami cacat bentuk yang sangat parah, terutama pada papan dengan ukuran panjang di atas $1 \mathrm{~m}$.

Dalam menetapkan suhu pengeringan, cacat yang terutama dipertimbangkan adalah pecah dalam (boneycomb) karena berperan penting terhadap penurunan kekuatan kayu dan sifat fisik lainnya. Salah satu penyebab terjadinya pecah pada bagian dalam kayu karena adanya tegangan-dalam kayu (growth stress) (Wang, et al., 1994). Tegangan-dalam kayu terjadi karena adanya perbedaan penyusutan yang sangat tinggi antara arah tangensial terhadap arah radial kayu (rasio $\mathrm{T} / \mathrm{R}$ ), sebagai akibat pemberian suhu yang keras di awal pengeringan pada kayu-kayu yang tingkat kesulitan pengeringannya tinggi (Rasmussen, 1961). Pada penelitian ini hanya kayu putat, petai dan terlebih lagi kayu mahang yang mengalami pecah pada bagian dalam kayu. Dari data penelitian Mandang dan Sudardji (2000), ukuran pembuluh kayu mahang sangat kecil. Hal ini mungkin merupakan faktor penyebab terjadinya pecah di bagian dalam pada kayu mahang, karena semakin kecil ukuran diameter pembuluh kayu akan memudahkan kayu untuk pecah (Panshin and de Zeeuw, 1969). Pecah dalam dapat ditekan antara lain dengan perlakuan pengeringan alami (air drying) atau pengeringan dengan menggunakan suhu kamar dan kelembaban rendah maupun pengaturan kecepatan angin (shed drying) sampai kadar air kayu mendekati titik jenuh serat, sebelum dikeringkan lebih lanjut. Hal ini telah berhasil dilakukan pada pengeringan kayu mangium (Basri, 2005).

Kerusakan kayu yang banyak dijumpai pada penelitian ini adalah pecah pada ujung dan permukaan kayu serta perubahan bentuk/deformasi pada arah tebal kayu. Pecah terparah terdapat pada kayu mahang (nilai skala IV-V), sedangkan perubahan bentuk terparah ditemukan pada kayu menjalin (nilai skala III-V). Pecah permukaan pada kayu terjadi pada awal proses pengeringan ketika kadar air kayu masih tinggi. Hal ini karena pada awal pengeringan bagian permukaan kayu mengering dengan cepat sementara bagian dalam masih basah sehingga terjadi ketidak-seimbangan tegangan tarik di bagian permukaan dan tegangan tekan di bagian dalam yang menyebabkan pecah. Menurut Rasmussen (1961), pecah permukaan dapat terjadi dalam jari-jari kayu, saluran resin maupun dalam lapisan 


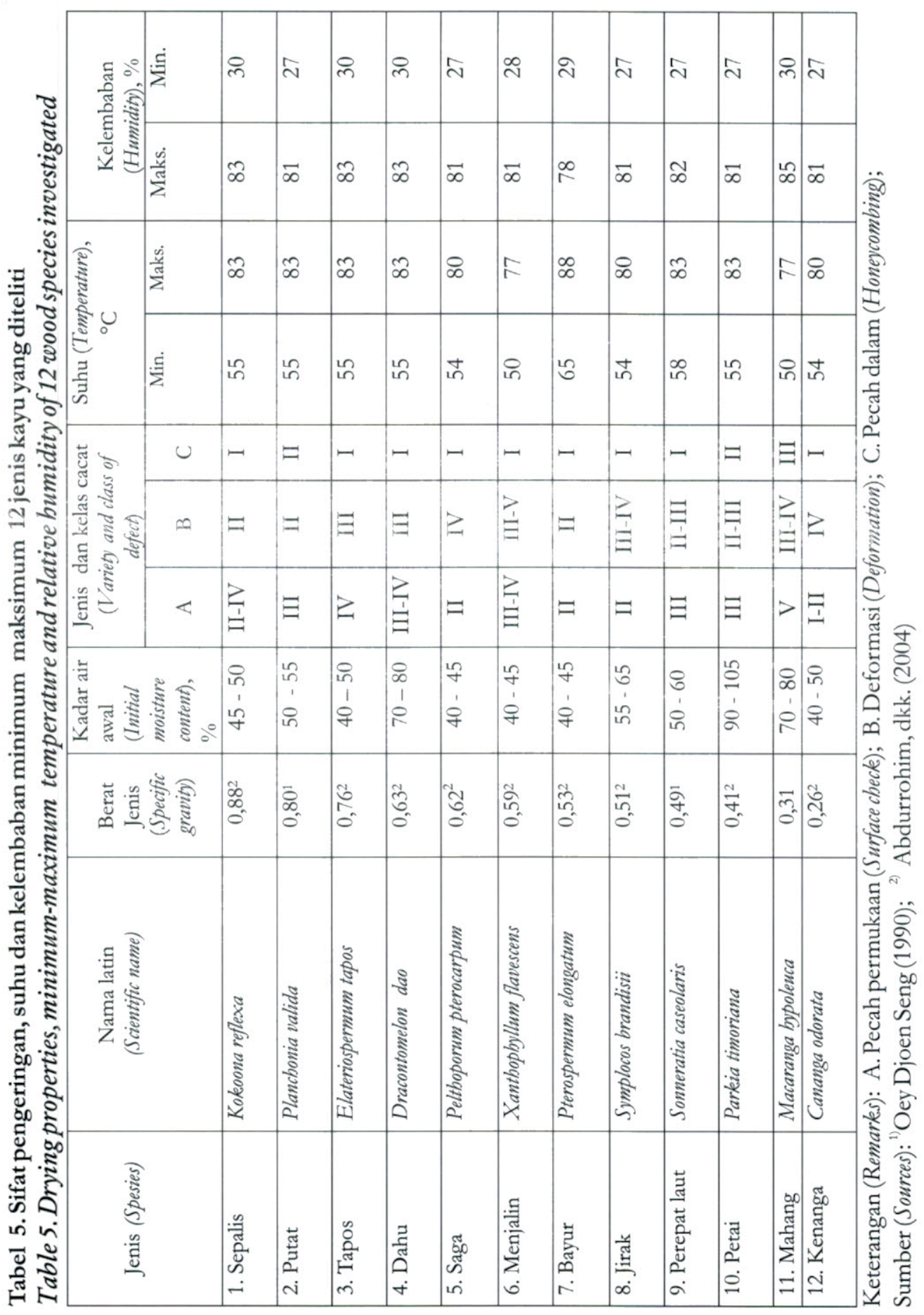


mineral. Pecah permukaan ini dapat ditekan dengan pemberian kelembaban yang tinggi atau perlakuan pengukusan pada awal pengeringan (Basri, et al., 1999).

Perubahan bentuk pada kayu dapat terjadi karena adanya perbedaan penyusutan dalam arah radial, tangensial dan longitudinal atau karena adanya kayu reaksi (compression wood), kayu tekan (tension wood), kayu juvenil (juvenile wood) dan mata kayu (Rasmussen, 1961; Bramhall and Wellwood, 1976). Pemberian beban yang cukup pada permukaan tumpukan bagian atas serta pengaturan jarak ganjal yang baik akan menghasilkan kayu kering berkualitas baik (Basri, 1990).

Dari 12 jenis kayu yang diteliti, kayu bayur memiliki sifat pengeringan terbaik dengan kelas cacat pengeringan I untuk pecah di bagian dalam kayu dan II untuk pecah ujung dan deformasi, sehingga dapat dikeringkan menggunakan suhu dan kelembaban minimum-maksimum $65^{\circ} \mathrm{C}-88^{\circ} \mathrm{C}$ dan $29 \%$ - $78 \%$. Sifat pengeringan terburuk diperoleh pada kayu mahang dan menjalin, sehingga keduanya hanya bisa dikeringkan menggunakan suhu minimum-maksimum $50^{\circ} \mathrm{C}-77^{\circ} \mathrm{C}$ dan kelembaban $30 \%-85 \%$ untuk kayu mahang serta $28 \%-81 \%$ untuk kayu menjalin.

\section{B. Bagan Pengeringan}

Hasil penelitian ke 12 jenis kayu di atas (Tabel 5), menghasilkan 8 kelompok bagan pengeringan kayu dengan suhu dan kelembaban minimum-maksimum yang sama. Dari 12 jenis kayu tersebut, kayu bayur memiliki sifat pengeringan terbaik, sedangkan kayu mahang dan menjalin yang terburuk. Berdasarkan bagan suhu dan kelembaban yang dikeluarkan oleh Forest Products Laboratory Madison (Torgeson, 1951 dalam Basri, et al., 2000), dan mempertimbangkan kadar air awal kayu yang akan dikeringkan, maka bagan pengeringan yang terkeras sampai yang terlunak untuk setiap jenis kayu dapat dilihat dalam Tabel 6 .

Bagan pengeringan di atas, di dalam penerapannya perlu dimodifikasi lagi dan bisa ditambahkan dengan perlakuan tertentu untuk mempercepat proses pengeringan tanpa menurunkan mutu kayu. Modifikasi bagan perlu disesuaikan dengan kondisi kayu yang dikeringkan, terutama dari ukuran sortimen. Hal ini dapat dimengerti karena ukuran dimensi contoh uji yang diteliti sangat kecil, sehingga tidak tampak cacat bentuk seperti membusur (bowing), memangkuk (cupping) dan menggelinjang (twisting).

Tabel 6. Bagan pengeringan 12 jenis kayu Indonesia Table 6. Drying schedule for 12 wood species of Indonesia

\begin{tabular}{|c|c|c|}
\hline $\begin{array}{c}\text { Kadar air (Moisture content), } \\
\%\end{array}$ & $\begin{array}{c}\text { Suhu (Temperature), } \\
{ }^{\circ} \mathrm{C}\end{array}$ & $\begin{array}{c}\text { Kelembaban (Humidity), } \\
\%\end{array}$ \\
\hline 1. Kayu bayur (Bayur wood) & & 78 \\
Basah (Green) -30 & 65 & 68 \\
$30-25$ & 70 & 56 \\
$25-20$ & 70 & 39 \\
$20-15$ & 80 & 22 \\
$<15$ & 80 & \\
\hline
\end{tabular}


Tabel 6. lanjutan

Table 6. Continued

\begin{tabular}{|c|c|c|}
\hline $\begin{array}{c}\text { Kadar air (Moisture content), } \\
\%\end{array}$ & $\begin{array}{c}\text { Suhu (Temperature), } \\
{ }^{\circ} \mathrm{C}\end{array}$ & $\begin{array}{c}\text { Kelembaban (Humidity), } \\
\%\end{array}$ \\
\hline \multicolumn{3}{|l|}{ 2. Kayu perepat laut (Perepat laut wood) } \\
\hline Basah (Green) -40 & 60 & 82 \\
\hline $40-35$ & 60 & 77 \\
\hline $35-30$ & 60 & 74 \\
\hline $30-25$ & 65 & 64 \\
\hline $25-20$ & 70 & 47 \\
\hline $20-15$ & 75 & 28 \\
\hline$<15$ & 80 & 22 \\
\hline \multicolumn{3}{|l|}{ 3. Kayu putat (Putat wood) } \\
\hline Basah (Green $)-35$ & 55 & 81 \\
\hline $35-30$ & 55 & 72 \\
\hline $30-25$ & 60 & 60 \\
\hline $25-20$ & 65 & 45 \\
\hline $20-15$ & 70 & 27 \\
\hline$<15$ & 80 & 22 \\
\hline \multicolumn{3}{|l|}{ 4. Kayu petai (Petai wood) } \\
\hline Basah (Green) -60 & 55 & 81 \\
\hline $60-50$ & 55 & 76 \\
\hline $50-40$ & 55 & 68 \\
\hline $40-30$ & 55 & 64 \\
\hline $30-25$ & 60 & 62 \\
\hline $25-20$ & 65 & 45 \\
\hline $20-15$ & 70 & 27 \\
\hline$<15$ & 80 & 22 \\
\hline \multicolumn{3}{|l|}{$\frac{\text { 5. Kayu sepalis, tapos dan dahu }}{\text { (Sepalis, tapos and dabu wood) }}$} \\
\hline Basah (Green) -40 & 55 & 81 \\
\hline $40-35$ & 55 & 72 \\
\hline $35-30$ & 55 & 60 \\
\hline $30-25$ & 60 & 43 \\
\hline $25-20$ & 65 & 38 \\
\hline $20-15$ & 70 & 27 \\
\hline$<15$ & 80 & 22 \\
\hline
\end{tabular}


Tabel 6. lanjutan

Table 6. Continued

\begin{tabular}{|c|c|c|}
\hline $\begin{array}{c}\text { Kadar air (Moisture content }) \text {, } \\
\%\end{array}$ & $\begin{array}{l}\text { Suhu (Temperature), } \\
{ }^{\circ} \mathrm{C}\end{array}$ & $\begin{array}{c}\text { Kelembaban (Humidity), } \\
\%\end{array}$ \\
\hline \multicolumn{3}{|l|}{ 6. Kayu saga, jirak dan kenanga } \\
\hline \multicolumn{3}{|l|}{ (Saga, jirak and kenanga wood) } \\
\hline Basah (Green) -35 & 50 & 80 \\
\hline $35-30$ & 50 & 71 \\
\hline $30-25$ & 55 & 60 \\
\hline $25-20$ & 60 & 52 \\
\hline $20-15$ & 65 & 43 \\
\hline$<15$ & 80 & 26 \\
\hline \multicolumn{3}{|l|}{ 7. Kayu menjalin (Menjalin wood) } \\
\hline Basah (Green) -30 & 45 & 78 \\
\hline $30-25$ & 50 & 71 \\
\hline $25-20$ & 55 & 60 \\
\hline $20-15$ & 60 & 43 \\
\hline $15-10$ & 70 & 27 \\
\hline$<10$ & 70 & 20 \\
\hline \multicolumn{3}{|l|}{ 8. Kayu mahang (Mabang wood) } \\
\hline Basah (Green) -40 & 45 & 83 \\
\hline $40-35$ & 45 & 78 \\
\hline $35-30$ & 45 & 69 \\
\hline $30-25$ & 50 & 60 \\
\hline $25-20$ & 55 & 43 \\
\hline $20-15$ & 60 & 26 \\
\hline$<15$ & 70 & 20 \\
\hline
\end{tabular}

\section{KESIMPULAN DAN SARAN}

Hasil penelitian sifat pengeringan 12 jenis kayu dari Nusa Tenggara Barat, Jawa Barat, Aceh dan Kalimantan Barat menunjukkan bahwa setiap jenis kayu memiliki respon yang berbeda terhadap perlakuan pengeringan suhu tinggi. Kerusakan kayu yang banyak dijumpai pada penelitian ini adalah pecah pada ujung dan permukaan kayu serta perubahan bentuk (deformasi) pada arah radial (tebal) kayu. Pecah terparah terdapat pada kayu mahang, sedangkan perubahan bentuk terparah ditemukan pada kayu menjalin. Dari 12 jenis kayu tersebut, kayu bayur memiliki sifat pengeringan terbaik. 
Berdasarkan sifat pengeringan kayu terhadap respon suhu tinggi serta mengacu pada bagan suhu dan kelembaban yang dikeluarkan oleh Forest Products Laboratory Madison yang mempertimbangkan kadar air awal kayu yang akan dikeringkan, maka dari 12 jenis kayu yang diteliti dapat diklasifikasikan ke dalam 8 kelompok bagan pengeringan.

Mengingat contoh uji untuk penetapan bagan pengeringan di atas ukurannya hanya 2 $\mathrm{cm} \times 10 \mathrm{~cm} \times 20 \mathrm{~cm}$, maka untuk aplikasi di industri perlu dilakukan modifikasi sesuai dengan ukuran sortimen yang diperdagangkan.

\section{DAFTAR PUSTAKA}

Abdurrohim, S., Y.I. Mandang dan U. Sutisna, edit. 2004. Atlas Kayu Indonesia Jilid III. Pusat Litbang Teknologi Hasil Hutan. Bogor.

Basri, E. 1990. Bagan pengeringan beberapa jenis kayu hutan tanaman Industri. Jurnal Penelitian Hasil Hutan 6 (7): 447-451. Pusat Litbang Hasil Hutan. Bogor.

Basri, E., H. Roliadi and Rahmat. 1999. The effect of pre-steaming and cross-sectional end-coating on the drying properties of Indonesian Torem (Manilkara kanosiensis) wood species. Proceedings of The Fourth International Conference on The Development of Wood Science, Wood Technology and Forestry, July 14 - 16, 1999 in Missenden Abbey, England. Pp. 206 - 211.

Basri, E., K. Hayashi, N. Hadjib and H. Roliadi. 2000. The qualities and kiln drying schedules of several wood species from Indonesia. Proceedings of The Third International Wood Science Symposium, November 1 - 2, 2000 in Kyoto, Japan. Pp. 43 - 48.

Basri, E. 2005. Mutu kayu mangium dalam beberapa metode pengeringan. Jurnal Penelitian Hasil Hutan 23 (2): 119 - 129. Pusat Litbang Teknologi Hasil Hutan. Bogor.

Bramhall, G. and R.W. Wellwood. 1976. Kiln drying of Western Canadian Lumber. Canadian Forestry Service. Western Forest Products Laboratory. Vancouver, British Columbia.

Kadir, K. 1975. Bagan pengeringan beberapa jenis kayu Indonesia. Laporan No. 57. Lembaga Penelitian Hasil Hutan. Bogor.

Mandang, Y.I. dan U. Sudardji. 2000. Anatomi dan kualitas serat dua puluh jenis kayu dari kawasan Barat Indonesia. Buletin Penelitian Hasil Hutan 18 (3): 163-208. Pusat Penelitian Hasil Hutan. Bogor.

Oey Djoen Seng. 1990. Berat jenis dari jenis-jenis kayu Indonesia dan pengertian beratnya kayu untuk keperluan praktek. Pengumuman Nr. 13. Pusat Penelitian dan Pengembangan Hasil Hutan. Bogor.

Panshin, A.J. and C. de Zeeuw. 1969. Text Book of Wood Technology, 3 rd. McGraw-Hill Book Co.,pp.150-197. New York.

Perré, P. 2001. The drying of wood: the benefit of fundamental research to shift from improvement to innovation. Proceeding of the $7^{\text {th }}$ International IUFRO Wood Drying Conference, July 9-13, 2001. Tsukuba, Japan. pp. 2 - 13. 
Rasmussen, E.F. 1961. Dry Kiln Operator's Manual. U.S. Department of Agriculture. Agric. Handbook 188.

Rulliaty, S. 1988. Beberapa jenis kayu yang dapat dimanfaatkan sebagai pengganti ramin. Sylva Tropika 3 (2): 26 - 28. Pusat Litbang Hasil Hutan. Bogor.

Terazawa, S. 1965. An easy methods for the determination of wood drying schedule. Wood Industry 20 (5). Wood Technological Association of Japan.

Wang, Z., E.T. Choong and V.K. Gopu. 1994. Effect of presteaming on drying stresses of red oak using coating and bending method. Wood and Fiber Science 26 (4): 527 - 535.

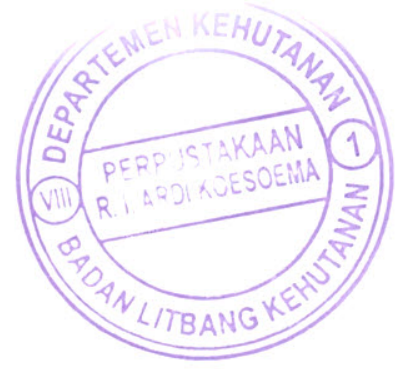

